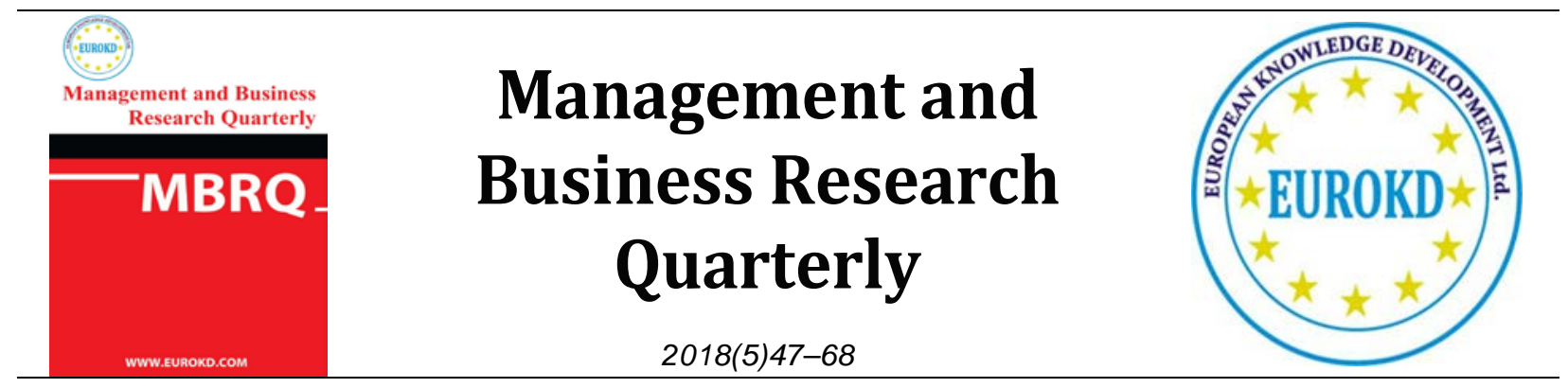

\title{
A comprehensive model for evaluating the performance of universities
}

\author{
Elnaz Ketabchi*, Ramon Salvador Valles \\ Polytechnic University of Catalonia, Spain
}

Received 28 October 2017 Accepted 15 May 2018

\begin{abstract}
Because schools are usually private (and small), So far, to measure the performance of them, the models specific to small organizations or purely educational organizations is used. In many countries, there are educational centers (and sometimes research centers) that Due to Antiquity of several decades, or due to Government supports, they have become to large organizations. Since many indicators used to evaluate the performance of such organizations, the necessity of a unified model to measure the performance of the whole organization (at all aspects), is felt. In this article underlying performance evaluation model of Kim (2014), and Put scattered indicators used to evaluate the performance of universities in this platform, a comprehensive model for measuring university performance is provided.
\end{abstract}

Keywords: Academic Performance, Performance Evaluation, University Performance Evaluation.

\section{Introduction}

A rational-goal model indicates that organizational performance can be measured by the extent to which organizational goals are achieved. Since the goals of universities are somehow ambiguous it is hard to conform a sure applicable approach (Kim, 2014). This measurement is very similar to the health checkup of a human body to see how each of function of body is well maintained (Wang, 2010). That is why this paper argues about the possibility of performance of universities measurement based on the extent to which each of university functions is maintained or improved 
toward the indicators targets upon the departmental goals. The performance can easily be divided into academic and managerial performances. Where the academic performance dimension, itself, can be further divided into research and educational dimensions which are themselves two traditional main areas of activities in most universities. The managerial performance dimension itself can be further divided into financial and human resource dimensions, both of which are the main enablers of performance in organizational management systems. Previous performance indicators and academic reports in higher education can provide some helpful guiding instructions on how performance indicators can be developed. Out-taking from the literature, some performance indicators will be collected and classified into the four sub-dimensions, and be discussed in terms of validity and reliability in the measurement, and cons and pros for management.

As can easily be concluded, multi-dimensional frameworks have been developed to cover broader organizational interests at both financial and non-financial areas (Wang, 2010). The balance scorecard (BSC) (Jeong, 2014), the Government-Linked model (Abu Bakar, 2015), are examples of multi-dimensional frameworks.

In this paper, collecting key indicators for assess the performance of universities in various papers, comprehensive model of university evaluation criteria will be proposed.

\section{University Performance Measurement Literature}

To begin with the discussions on the literature gap of performance measurement, we need first to understand what the studies on universities performance have done so far; this way, we can define what they had not done yet. Wang (2010) believes, there is no unanimous definition for organizational performance because when the industry varies, the PM mechanism loses its entity. A definition of organizational performance without considering the actual organizational context might be faint. Efforts on clarifying organizational performance are still vague and loosely define the construct in the relative field of study (Lee, 2010). Thus, the organizational performance can be measured by the extent to which the departmental goals are achieved. This will, in turn, be defined as the extent to which the KPIs have approached to their targets.

Brief reviews of PM and organizational theories still have not solved the problem of what scholars might be looking at. A widely accepted performance measurement definition is of ElHefnawy et al. (2014) which is the process of quantifying the efficiency and effectiveness of actions. The measurements are expected to be multi-dimensional, which depends on how people interpret the "efficiencies". For example, if one of a hospital's goals is to provide treatments and cares for patients who are suffering from a variety of diseases and incidents, then the measurements on efficiency ought to cover aspects such as the number of patients cured in each category of illnesses, the average number of days a patient stay in hospital and the average amount of time each doctor spends on a patient etc. The measurements will require considerable numbers of multidimensional indicators in tracking every characteristic of hospital services. The measurements on effectiveness are also multi-dimensional, and depend on how the "effectiveness" of a specific organizational goal is interpreted. 
Many studies have just paid attention to the academic performance of a university, while it is inevitable that managerial aspects of a university also can influence on the success. Especially, the life of the private sector in the highly depends on the financial factors of the organization. On the other hand, the shortcomings of reliance only on financial indicators might causes managers ignore other aspects or prefer short-term successes than long-term improvements leading to a distant Excellency. Inadequate attentions to other aspects such as human capital causes organizations fail in their objectives fulfillment, because the main instrument of organization movement toward its utter destination is the people who work for it. The literature mostly covers the single dimension approaches of universities PM which is mainly because of the ambiguous objectives of universities as organizations.

\section{The KPIs for University Performance Measurement}

A thorough penetration through the literature shows there are some KPIs which should be supported by data of high quality in four main categories which follows. The development of performance indicators should follow the characteristics of relevance, economic feasibility and institutional acceptability etc. (Wang, 2010). The development of indicator also requires a consideration on what kinds of performance indicators which are most applicable to objects being measured. For example, qualitative indicators might be more helpful than quantitative indicators in measuring people's attitude and satisfaction etc.

The following refers to metrics that are important for the functioning of the universities:

\section{Research Performance Indicators}

Research activeness is the most usual factor which determines a university's academic reputation which is an important source of new knowledge as well, often even appears in a university's mission statement revealing what the university actually does or wants to do. It is sometimes throw the other aspects out of the game as a mistake of the managers. The indicators include the number of researches from sponsors and researchers FTE, the number of publications, citations, the number of awards and memberships, etc.

Researcher FTE - The FTE- Full-time equivalent- is a popular measure showing the involvement level of researchers in research activities. It is measured by the amount of time with which an employee is involving in research projects. If an FTE equals to 1, an employee's level of involvement in research activities is evaluated as full-time, for example, 40 hours a week etc. but the FTE of 0.5 shows half of the amount of time the employee with 1 FTE. Counting employees with different scores in FTE, university managers are able to know how many employees are completely committed to the research activities or how much percentage of employees is with different FTE scores. Most research activities are carried out by PhD students and academic staff in universities. The FTE provides the managers with an acceptable approach to measure employees with different level of involvement in research. Nevertheless, the results from FTE are calculated from the standard amount of time laid down in contracts. It is not clear how much the FTEs provide a reliable measurement on actual input of time by researchers. To PhD students, overtime work is 
quite a normal phenomenon. Therefore, the FTE may only provide university manages with a measurement of researcher's involvement against standard amount of time in labor contacts (Wang, 2010).

The number of researches from sponsors- With increasing external funding from outside organizations, universities may employ researchers from sponsors to co-participate in research programs as parts of agreement. The indicator can be measured by the number of people paid from external grants. The more researchers from external grants in cooperation, the more connections with external organizations a university could have in research networks. It also signals the university's research influence at its fields.

Successful research granted applications - This indicator measures the total number of granted applications for a wide range of research programs. A similar indicator can be the ratio of successful research grant applications in the CUC- Committee of University Chairmen- report (2006). The indicators signal the general research strength of a university in competing for research resources and the quality of research proposals. Research programs can be divided into a few levels of international, national and inter-institutional. Successful research grant applications by international and national level sponsors can be considered as high achievements for a research scholar. International and national level research programs from research councils and international institutions may require an applicant with higher academic achievements in certain fields. Not all applicants may meet eligibility criteria to the category of research programs. Besides, an applicant may face fierce competition by other scholars from different universities at home or abroad. Thus, it can be considered as a valid indicator in research performance measurement.

The number of successful research grant applications can also be measured by other research programs in non-governmental institutions. The research programs may open to large group of applicants with less strict requirements attached than programs from research councils. Thus in the measurement of research performance, they may not be as valid as research granted applications from high level research programs. In addition, factors influencing the success of application cannot be ignored. The factors may include the scientific topics addressed in applications, popularity of research topics related to university researching fields and research budgets etc. The reliability of indicator for university managers in the measurement of research performance should not be over-estimated. The indicator may also subject to broad economic influence in the measurement. In years with good economic condition, the number of successful applications may increase significantly when compared with years in bad economic conditions. To university managers, the indicator is also a measurement of university's systematic supports and trainings for researchers to apply for research programs rather than the performance of scatter-guns by the large number of applications (Hou, 2014).

Besides, the number of successful applications can also be measured by monetary terms e.g. euro. It provides managers in universities with an annual sum of research granted funds which can be compared with the amount of funds granted in previous years. Again, because of broad economic influence and size of research budgets from the applications, the reliability of the 
measurement might be compromised. In extreme case, one successful application can generate great proportion of research funds to total research granted funds.

The number of strategic partnerships - The strategic partnership is a formal agreement between a university and external organizations, which the parties share the information, know-how and support common objectives. It is also an important source of research funds and sponsors as well. Partners in the agreement could cover all business areas, from venture capitalists to governments, from technological companies to universities. The strategic partnership establishes a channel that common interests can be pursued for benefits in areas of interests by involved parties. With increasing strategic partnerships, the university can eventually form a knowledge transfer networks. Thus, it is an important input indicator to the university in the CUC report (2006). The more strategic partnerships the university is engaged in, the more diverse of sponsors could be. The indicator can be measured by the number of strategic partners that the university has formal agreements with. It is a valid and direct measure on quantity of partnerships that the university has. However, it may not be very reliable in measuring quality of strategic partnership which affects the actual amount of value might be created in cooperation. The indicator provides a quantitative measurement on the university's engagement in connections with external organizations.

\section{Research Output Indicators}

The number of publications - In output measurement, the use of indicators such as the number of publications is a frequent quantifying measure on research outputs. The indicator is simple in use but the information from it is limited because little is known about the quality of these publications and how profound of the publications can produce is unknown. Thus, a problem here is how to judge the quality of publications, in other words, how prestigious journals and conferences where paper gets published can be seen as a good indicator of excellent research performance. The publications can be measured by refereed journals, non-refereed journals, conference, books and chapters of books etc. Refereed journals can also be divided into ISI refereed journals and non-ISI refereed journals. ISI journals are the most frequent used academic journals categories in worldwide. ISI journals provide a relative high valid and reliable measurement on the quality of publications. ISI refereed journals, books and refereed chapters in books published by world top publishers can generally be considered as good quality. The publications are carefully examined by publishers in content for a long period of time and they mainly serve academic purposes. To non-ISI refereed journals, non-refereed journals and other non-refereed publications by some not well-known publishers, it is unclear whether the publications can be regarded as good quality or not. The publishers may lack of mechanisms in prudently assessing the quality of publications or they assess publications by low level of criteria (Adriana, 2008).

To conference publications, university managers face the same problem in validity and reliability issues. Conference publications can be categorized into refereed paper and non-refereed paper by different levels of conferences. For example, ISSCC (International Solid State Circuits Conference) is the best in electronic engineering. Paper there tend to be considered as top quality 
ones in the field because they have been reviewed by experts before publication. However, researchers can also submit their papers to some small conferences such as IEEE International Midwest Symposium on Circuits and Systems. To non-top conferences, it is unknown whether paper get published there is good or not. The validity of the papers in non-top conferences in measuring research performance might be compromised by low level of acceptance criteria. To non-refereed paper, the validity of measurement in research performance is low. Therefore, the indicator of the number of publications still needs subjective judgments by university managers on whether the publications are considered as good research performance or not. The indicator lacks the reliability in the measurement on quality of publications. The indicator may unexpectedly lead research personnel to chase for quantity instead of quality of publications if ISI refereed journals and top conferences are not emphasized (Barnabe, 2007).

The number of doctorate conferred - The number of doctorate conferred is an output indicator in research performance measurement. It counts the total number of doctorates conferred to $\mathrm{PhD}$ students annually. $\mathrm{PhD}$ students constitute a research university's main research groups. When they graduate, they also become the university's research outputs as well. Thus, it is a relative valid and reliable measurement in research performance. It provides managers with a total amount of doctorate degrees in the university, which can be compared with the performance in other universities in the country (Broadbent, 2007).

Exploitation of Intellectual Property (IP) - Exploitation of IP is an output indicator for a university to measure how effectively she has used IP for economic benefits. In the CUC report (2006), the indicator is put under the dimension of knowledge transfer and relations. The indicator can be measured by the number of spin-off companies, license agreements and patents etc. The number of university spin-off companies measures how well the university has transformed intellectual property, technologies into new products with commercial value into market places. A spin-off company usually starts life within the university and later progresses to be an independent business organization on its own endeavor. The higher number of spin-off companies, the higher performance the university will be in exploitation of intellectual property. Thus, exploitation of IP by the number of spin-off companies is a valid measure. Because of close relations with the university at initial stages of development, spin-off companies can be seen as reliable measure in the measurement of a university's IP exploitation.

The number of license agreements signed measures a university's commercial effort in utilizing its intellectual property in exchange for economic interests. Thus, it is a valid measure of the university's effort in exploitation of IP. However, the number of licenses the university can successfully issue is affected by external demands and criteria in the agreements. If there is no demand by customers or both sides cannot reach the agreement, there will probably no license agreements by the university. No license issued does not necessary mean poor exploitation of IP in the university. Thus, the reliability of this measure in measuring exploitation of IP should not be overestimated. The number of patents granted is another measure in exploitation of IP. A university can secure its research achievements by applying for patents from governmental institutions. Patents are sources of competitive advantages as well. The patents could be seen as a 
first step for commercial exploitation of IP. However, with regard to the value in the patents, it is the outputs of the patents that matter rather than the sheer number of patents. A university with hundreds of patents that are never to be commercialized will not produce the same amount of economic benefits as another university with only a few successfully commercialized patents does in exploitation of IP. Thus, it could not be a very valid measure in the measurement. The indicator of exploitation of IP measured by the number of spin-off companies, patents and license agreements is a way to see how well the university has made effort in utilizing its research outputs in a commercial way. However, with regard to actual value of exploitation of IP, it is the amount of economic benefits that matter to the university. The information from the indicator is limited in this aspect (Chen, 2006).

The number of successful entrepreneurs - The number of successful entrepreneurs may also be one of output indicators in research. It quantifies the total number of students and university staff who become entrepreneurs with research background in the university. An entrepreneur can be seen as a person with passions and ambitions to be an enterprise with bears of risks and benefits. It is also a passion to create value with knowledge, skills and techniques learned from research activities in the university. Thus, it is an important process of transferring research outputs into real business applications. An alternative measure is the growth rate of entrepreneurs, which it counts the incremental percentage of people who become entrepreneurs. However, to become an entrepreneur is a matter; to become an entrepreneur who succeeds is another matter. It takes time to justify. Besides, it is unclear the extent to which criteria can be used to evaluate a successful entrepreneur or not. The validity of indicator used in research performance measurement may not be overestimated (De Boer, 2007).

\section{Research Outcome Indicators}

Citation - Citation is a widely applied indicator on quality of publications. It counts the frequency of quotations from a specific source appeared in other authors' publications. It provides a helpful method for people to scientifically measure the quality of publications. Citation by impact score is a widely applied tool in ISI publications. It measures the average number of frequencies of published papers are citied usually two years after publication. However, it also subjects to deficiencies in the reliability of scientific counting. Lehmann and co-authors (Lehmann et al. 2008) argued that because of the asymptotic power-law distribution of citations in all kinds of websites, the average number of citations under a given author may be unreliable due to fluctuations of sample means in selection. It also suffers criticisms because of limited use only in ISI publications and self-citations. Furthermore, the impact score to a given author may be manipulated by the increasing number of review papers which may boost the impact score. Thus, it may have validity and reliability issues in research performance measurement.

An alternative approach in measuring citations is the $\mathrm{h}$ index. The $\mathrm{h}$ index can be applied to wide ranges of objects including individuals, departments, faculties and universities. El-Hefnawy (2014) explains that "a scientist has index h if h of his or her Np papers have at least h citations each and the other (Np-h) papers have $\leq \mathrm{h}$ citations each". The advantage of $\mathrm{h}$ index for 
management is a measurement on both quantity and quality of publications. The disadvantage of $\mathrm{h}$ index is still largely dependent on manager's intuitive judgments on citation data. The index is not amenable to quantitative investigation in the measurement of scientific research performance of people especially when such citation data are used in evaluation of promotion and appointment (Lehmann et.al 2008). For example, if an author has 12 papers with each at least 12 citation, then the index is 12 . When compared with another author has with 16 papers within which 12 has been citied at least 12 times each and the rest is less than 12 times citations, the result of $\mathrm{h}$ index is still 12.

Another disadvantage in the measurement might be lack of time based concern. The $\mathrm{h}$ index depends on the accumulation of an author's publications and citations over time (El-Hefnawy, 2014). The longer an author works the larger $h$ index he or she may have accumulated. While in research performance measurement on a regular basis, a problem arise at whether very past performance records should still be used in current performance measurement. The H-index may purposely boost performance with very historically data in updated measurement of research outcomes. Besides, the h-index focuses on papers with most cited records that may give rise to biased comparisons among institutions. Sypsa and Hatzakis (2009) concerned that "An institution with a moderate-size production will not reach the h-index of a very large institution even if the quality of its publications are of similar or even better quality simply because its total production may be even less than h."

For university management, citation provides managers with a widely recognized tool in the measurement of research publications. However, citation is a very time-lagged indicator as discussed by different measures above. It may take years until a publication of a given author is citied. Therefore, the validity of the indicator for management in research performance measurement of a given research group might be compromised due to flow of researchers and accumulation of citations.

Membership of research council and editorship of ISI journals - The indictor counts the number of people with membership in research councils and editorship of journals. It may signal a general research reputation and research strength of a university. Thus, it might be a helpful indictor for university management. Research councils may include both national and international research councils. ISI journals are the most frequently used and highly recognized journals in academic world. To become a member of research councils or an editor in ISI journals may be a great honor to a researcher in the field. The indicator can be measured by the number of editors in ISI journals and the number of board members in research councils. They provide a measurement by counting the total number of people with titles in these organizations. However, the validity of memberships in research councils and editorships of ISI journals in current research performance measurement of the university may not be overestimated. Most likely, it is because of the researcher's past research performance that leads them to the positions in the prestigious organizations. There might be even no definite casual relation between research performance and their positions in these organizations. Thus, the validity of membership for university managers in research performance measurement of a university is a question mark (El-Hefnawy, 2014). 
Awards - Award is an outcome indicator in research performance measurement, which is also used in the CUC report (2006). The indicator counts the total number of awards people received from outside research organizations. For example, the NWO Spinoza prize, also called "Dutch Nobel Prize”, is a national-wide award to researchers for great contributions in research activities. One of winners in 2009 is Prof. Albert van den Berg. The NWO Spinoza prize is a well-recognized award in the country with high reputations. Thus, it can be considered as a valid and reliable indicator in research performance measurement. Besides, in journals and conferences, researchers can also be awarded by "best paper" to their publications in their research fields. Because of various types of awards, the validity of the measurement to university managers might be compromised. High-level awards are recognized by most people and they bring with high reputations to researchers. The indicator depends on manager's subjective judgment on the value of types of awards. The reliability of awards in measuring research performance is a problem for different types of awards. The indicator of awards is simple to use but it might be not practical on a regular basis. The chances of actual use of the indicator might not be very often because awards are rare to happen.

Research ranking - Ranking can be an indirect measure on research performance in universities. It measures the ordinal numbers of each research subject by different criteria. One of well-known research rankings is from University of Leiden, commonly known as Leiden Ranking. The ranking can be done by selection of different fields, scopes and period of time on the basis of composed indicators in research. Thus, it provides a relative valid and reliable measurement to measure the university's research performance. The use of Leiden ranking is very simple for university managers with all the information provided from its website. Thus, the measurement can be done any time the managers feel the measurement is necessary. An alternative approach is research assessment by peers' reviews. Research performance in universities can be rated by experts outside the universities. Their ratings can also provide a relative objective measurement for universities (Bird, 2005).

\section{Educational Performance Indicators}

Educational performance may be another pillar that underpins a university's academic reputation. It is a traditional and standard dimension in performance measurement in universities. Educational performance indicators will cover the whole educational process from input, process and output till outcome.

\section{Input Indicators}

Intake of graduates and undergraduates - Past indicators on input measurement by student's entry qualifications and initial abilities has been unsatisfactory (Jeong, 2014). These indicators only measure what students bring into universities and they may not have direct links to the subsequent performance of students. Current indicators on input measurement have been focused on measuring the number of intake of students. The number of enrollments for undergraduates and graduates or market shares of students are used as input indicators. However, the linkage between 
educational performance and the number of enrollments is unclear in whether educational performance precedes the number of enrolments or vice versa. Strictly speaking, the indicators lack validities in the measurement of educational performance. Besides, the indicators may also have reliability problems because students' preference to some universities may directly influence the number of enrollments in other universities in the country. The indicators of intake of students can be separated into intake of bachelors and masters. Intake of students in bachelor programs includes indicators such as the number of intake of 1st year students, the number of intake of international students in bachelor programs and the number of intake of EU students in bachelor programs. Intake of students in master programs includes indicators such as the total number of intake of internal master students, the number of intake of international masters and the number of intake of EU master students. The indicators aim at measuring the demographic characters and socio-economic backgrounds of students by classifying them into different groups. All the indicators can be measured by the number of enrolments in universities. The measurement can be compared with the actual number of intake of students against university targets. Thus, it is a valid and reliable approach to measure intake of graduates and undergraduates. The indicators provide university managers with a clear image of coming student's characteristics (Marz, 2012).

The number of BA/MA degree programs - The indicator measures the total number of degrees in bachelor and master programs that students can choose from. It emphasizes on the variety of degree programs to meets diverse needs of students. An alternative measure may be students per degree programs. The measurement can provide university managers with effective and reliable guidelines in appropriate investment of resources in degree programs. Another alternative measure may be the number of honor degrees. It measures the number of competitive honor degree programs the university has to attract talent students. The honor degrees are great acknowledgement of success to students with higher study results. It is more difficult for students to achieve than normal degrees in bachelor and master level. Thus, the honor degrees may mean higher level of educational performance for the university. The measure provides the managers with a clear image of how competitive their degree programs are (Mathew, 2011).

Staff FTE - The FTE may be a measure of staff's involvement level in educational activities as well. It is measured by the amount of time an employee is involving in educational activities. It is similar to the researcher's FTE discussed in the research dimension. By counting staff with different scores, university managers may be able to know how many percentages of academic staff are fully committed to educational activities or how many percentages of academic staff are with different scores of FTE in educational activities. The FTE may provide the managers with a valid and reliable measurement approach to distinguish staff from different levels of involvement in educational activities (Kim, 2014).

Student/academic staff ratio - The student/staff ratio indicates a general strength of teaching force to students in education, which is also used. The indicator can be measured by the ratio of number of full-time students to academic staff. The measurement may provide university managers with a ratio of how many academic staff is needed for the number of full-time students on campus. Though the indicator provides a ratio of the number of required academic staff to students, 
managers may not immediately take actions to improve the ratio due to financial constraints and recruitment timing etc. Thus, the usefulness of this indicator for university managers may be discounted (Lee, 2010).

\section{Process Indicators}

Renaud and Murray (2007) justified the use of higher-order questions in assignments as a process indicator in educational performance measurement and argued that the use of higher-order questions will improve student's critical thinking skills. Pascarella and Terenzini (2005) presented that previous process indicators such as size of libraries and facilities cannot be seen as valid measures because they unlikely have a strong connection with student outcomes. Their argument is further explained by Renaud and Murray (2007) that pervious indicators on size of libraries and facilities are selected on the basis of expediency and presumed relations with student outcomes. The indicators are far removed from what are actual happening in classrooms. In this paper, the emphasis of process indicators is on students because it believes students are the master of themselves and they directly involved in the production of educational service. Their satisfaction, complaints and overall opinions might directly affect their perceptions on the quality of educational activities, which ought to be severed as more reliable process indicators than the higher-order questions. Neely (2007) noted that in many universities, little attention has been paid to measuring expectations and satisfaction of students and even less to the people working there. Student satisfaction - Student's satisfaction toward educational activities is an important indicator in measuring educational performance in universities. As both customers and producers, student's experiences and opinions can produce valuable information on the quality of educational activities. The indicator is used both in CUC report (2006) and Australian Government report in higher education (2005). It measures the student's satisfaction level in the educational process. It is a relative broad concept in measuring student's satisfaction toward variety of objects. Similar indicators are proportions of students satisfied with overall facilities, proportions of students satisfied with teaching method, course programs, and information services and so on. The measurements can be done by student's evaluations by internal surveys to cover a wide range of student populations. It is a valid and economic method in measuring the satisfaction level of students. Though it is an easy way in the measurement, cautions should be raised by the reliability of data from the surveys. Data collected in the surveys may subject to all kinds of biases because of subjective judgments by students. The perceptions by students on educational activities are influenced by emotions, expectations and motivations overtime. Thus, the results from the indicators can only be referential in educational performance measurement.

Study efficiency - The indicator measures student's efficiency of studies in universities. It can be measured by the average amount of time students need to complete their study in bachelors, research masters and non-research masters programs. A similar indicator is progress rate from Australian Government report in higher education (2005). It provides a basis on which student's efficiency of studies can be compared with the required amount of time. For example, the bachelor

programs are 3-year study programs. The longer the students need to complete beyond the required 
amount of time, the low efficiency of their studies could be. Thus, the measurement could be a valid approach in measuring study efficiency of students. However, in some cases, students may choose to work ahead of having their diplomas. The reliability of the measurement in efficiency of studies may not be overestimated. For university management, it provides a helpful tool to get to know what the average amount of time each category of students are needed to complete their studies.

Retention rate - The indicator measures the percentages of students who remain in study from first year to second year in the same institution. It is a measure to see how many percentages of students have progressed after first year's study or how attractive a university to students could be. It is also used in the Australian government in higher education (2005). Student's retention rate is not only affected by educational performance perceived by students in the first year's study, but also is affected by student's behaviors and other academic mechanisms by principals. The retention rate might be especially useful for Homeschools whose policy of minimum 48 credits will screen a lot of students out after first year's study. The indicator can be used as a quality control mechanism in educational process especially in Homeschools. To universities in the Netherlands, effects from the indicator in application might not be obvious. In rare situation, the retention rate may drop significantly without such a screening policy.

Drop-out rate - The indictor measures the percentages of students who have dropped out during their studies for various reasons. It is an opposite indicator to the retention rate. It is calculated by the number of drop-out students divided by the annual number of enrollments. The indicator can be measured in bachelor and master levels (Broadbent, 2007). Though the number of drop-out students may not directly relate to the educational performance of a university, it might be an important indicator to see how the university has made efforts in keeping their students on campus. The measurement by different degree programs provides a detailed assessment on the drop-out rate in the university.

Average contact hours - The indicator is measured by the average amount of time per week that academic staff set aside for bachelor and master students to discuss problems in study. During the scheduled contact hours, students can directly go to teachers' offices to discuss any study problems face to face. Thus, the measurement by average contact hour per week may produce clear information of what the university has contributed to students during the process of education. The average contact hours might be used as a mechanism in universities to increase the study performance of students but the actual efficiency of how students has utilized contact hours are unknown to university managers. The effect of indicator for management use is limited.

\section{Outcome Indicator}

Output and outcome indicators are prevailing in all kinds of performance measurement reports (CUC report 2006, Australian Government 2005, etc.). Most widely used indicators in these reports cover graduation and employment.

Graduation - Graduation is a direct output of educational activities in universities. The Indicator can be measured by graduation rate in percentage of students who complete their studies on time. 
It is an effective measure to calculate how many percentage students have managed to graduate as a result of educational services in universities. Similar measures are the number of diplomas and the number of students graduated yearly. Results from the measures may fluctuate year by year due to the size of student population, delays in studies and continuing studies etc. Therefore, the reliability of the measurement might be compromised. Universities may even purposely loosen graduation criteria for sheer increase in the number of graduates if too much emphasis is put on the indicator.

Graduation satisfaction - Graduation satisfaction is an outcome indicator which measures the general satisfaction among alumni to universities. It produces an overview of graduation satisfaction usually months after students who graduate. The indicator can cover a broad range of topics including skills and knowledge, preparation for jobs and their opinions of educational programs in universities etc. The measurement can be done by asking students to register in alumni websites or using surveys. Thus, the measurement can provide valuable feedbacks for university managers in evaluation of university services from student's perspectives. Because of subjective judgments by students, the results from the surveys may only be referential.

Employment - Employment rate measures the percentages of graduated students who are employed full time after graduation to the total number of graduates. It shows the competitiveness of graduates from universities in labor market as part results of educations and training. However, results from the indicator only represent a narrow picture of graduate's employment's situation. Student's employment is affected by factors such as self-employment and continuing studies. Thus the reliability of employment rate as an indicator in educational performance measurement should not be overestimated. One alterative measurement of employment is the average level of starting salaries that students are able to get from their first jobs after graduation. Due to broad economic influences on employment, the reliability of the measurement should not be over-estimated. However, the measurement can generate much information about starting salaries by students with different degree programs in labor markets. Student's employment situation can also be measured by employer's feedbacks about student's working capabilities. The feedbacks may provide some helpful information about employer's general satisfaction toward students on the job but the reliability of information in measuring employment situation might be compromised by size of surveys and employer's subjective adjustments etc.

\section{Management Performance Indicators}

When universities develop policies and take actions toward achieving organizational goals in management, they may thirst for information that could both predict future directions and justify their past actions. In universities, the task might be complicated and difficult. Managers may face constant less input of resources but increasing demands for outputs with desired outcomes. Managers needs to be cautious of every move in developing, planning and execution of university policies and tasks. Performance indicators can provide university managers with early warnings if things go wrong and directions where actions can be taken (Parmenter, 2007). 


\section{Financial Performance}

Research activities in universities require considerable capital investment. Abundance of funds may play a critical role in research outputs and hence the level of research performance in the universities. Thus, the amount of financial resources is critical to the university's academic performance. Besides, effective financial management of resources is also important to the financial performance of universities. Financial performance indicators will focus on these two aspects in the universities (Zuashkiani, 2011).

\section{Financial Resources}

Amount of research income - The indicator counts total the amount of income related to research activities in universities, which is also used in CUC report (2006). It can be measured by the amount of research granted funds and research incomes. The amount of research granted funds counts the total amount of funds from research applications and sponsors. It discloses a symbol of research strength in financial point of view. The amount of research income from commercial activities counts the total income from trade of patents and license agreements etc. There are two sources of income for research activities. The indicator hints an important financial capability of universities in acquiring resources for research activities. However, a research project with large amounts of research funding granted may take years for a research group to complete before any new funds that might be contracted. Therefore, university managers may need to pay attentions to the influence of large research programs that affect the subsequent capabilities in contracting research funds. The reliability of indicator in measuring financial performance in universities might be compromised.

Research indirect cost recovery - One notable indicator related to contracting research funds is research indirect cost recovery contribution as percentages of total research income. The indicator has been used in the performance measurement in University of Edinburgh. The indicator measures the amount of contributions paid for research indirect cost recovery to the total research income contracted. The research grants and research contracted funds usually account for a certain percentage of research full direct cost. The remaining cost must be covered by universities. The indicator is especially useful in contracting research funds for university managers. The higher the indirect cost recovery, the less cost the universities needs to bear. It is a valid indicator to measure financial performance in terms of acquirement of financial resource. The reliability of this measure may be affected by the maximum amount of funds the sponsors can supply with. The indicator can provide the managers with a basic percentage from historical data to check how many new funds are required to contract (Jeong, 2014).

Share in third-party funding and share in governmental funding - Diversity of funding sources may be becoming an important criterion in financial performance measurement in universities. It signals a kind of capability and competitiveness of universities in acquiring diverse sources of financial resources. It is also an ambition for universities to be self-sufficient and secure in funds sourcing. The indicator of third-party funding measures the percentages of funding to universities from competitive funding sources. Third-party funding may include funds from private companies, 
research councils and donors etc. The indicator of share in governmental funding measures the percentage of funds directly from the governments. The higher the percentage of third-party and governmental funding, the higher financial performance the universities could be. As a financial indicator, the results from the indicator may fluctuate by the amount of funds the sponsors can supply with (Kim, 2014).

Income from tuition fees and other services - Tuition fees are one of the main sources of financial resources to universities. It can be measured by the amount of tuition fees in categories of national bachelors, international and European bachelors, national masters, international and European Masters and other university services etc. Income from other university services may include income from renting facilities, income from retail services within university etc. The measurement provides university managers with classified sources of income from different groups of students and other university services. Therefore, the managers are able to know what the exact amount of income from these specific sources is (Lee, 2010).

\section{Financial Position}

Financial position or financial condition may be an overall indicator in financial performance measurement. It contains both short-term and long-term financial position. Short-term financial position primarily concerns financial condition of an organization within one year. Accounting ratios and financial results are main tools in the measurement. Long term financial position is about strategic and long-term financial status of an organization for more than one year. Effective financial strategies are vital to lead managers to achieve long-term financial health in the organization. University managers may look at these indicators as a preliminary diagnosis of whether a university is able to be financially sustainable toward its objectives (Abu Bakar, 2015).

Short-term financial position - The kinds of financial results and accounting ratios to be used as financial indicators are institutionally defined. They depend on university environments and managerial choices. The CUC report (2006) and University of Edinburgh provide some financial indicators that include operating cost recovery, surplus/deficit as \% of income and current ratio. Besides, ratios such as administrative cost per FTE student, utilities and maintenance cost per FTE student and other expenditures per FTE student are also used in the measurement of cost varieties in universities (El-Hefnawy et al. 2014).

Operating cost recovery - Operating costs are expenses that are related to university's operating activities. They include all kinds of variable operating costs such as maintenance cost and repairing cost. Operating costs usually vary with the level of university outputs. To offset the recovery of operating cost from associated benefits in use, the operating costs are recovered from university's revenue. The indicator is measured by the ratio of operating costs to total university revenues. It is an indicator to measure how much revenue is needed for matching the incurred operating cost in the university operating (Hou, 2011).

Surplus/deficit as \% of income - The indicator measures a percentage of surplus or deficit in proportion to total university income. The surplus or deficit is the difference between university income and university expenditures. When measured by percentage of income, it indicates the 
percentage of surplus can be left for next year's operating or the amount of deficit must be covered by next year's revenue. It is very helpful for university managers to use the indicator as a control mechanism in budget planning (Adriana, 2008).

Current ratio - The indicator measures the financial strength of universities to see how much current liabilities are covered by current assets. Because universities barely have any inventories, most current assets are quick assets that are easily convertible into cash. The larger the ratio, the great financial strength of the universities is (Barnabe, 2007).

Debt ratio - The indicator indicates a percentage of university assets are provided by debts. It is measured by the ratio of total liabilities to total university assets. The larger the ratio, the higher amount of assets is financed by liabilities in the university. A high debt ratio might cause university managers lose control on expenses and discourage lenders from loans in the future (Broadbent, 2007).

All these short-term financial indicators are frequently used in the measurements in universities. They provide helpful tools for university managers to measure financial positions in universities. The reliability of the measurements by financial indicators depends on the accuracy of information published in financial statements and reports in universities. The indicators also provide the managers with simplified explanations of financial statements, a basis of comparison with past records and helpful tools in planning and forecast. One potential disadvantage on financial indicators is that too much emphasis on financial indicators may cause the managers myopia and may sacrifice long term development opportunities for short-term benefits (Bird, 2005).

Long-term financial position - Long term financial position is about strategic and long-term financial status of an organization for more than one year. Like other non-profit organizations in public sector, universities may need financial strategies to guide managers in appropriate financial management with lower risks. University's long term financial position may be measured by the effectiveness of financial strategies in severing financial management. The measurement is an ongoing and empirical process to see whether financial strategies have provided constructive contributions to university financial management. Another alternative measurement is by the amount of investment in infrastructures. The infrastructures provide the basic needs for universities to achieve long term development (Chen, 2006).

The investments will also affect the long-term financial position in the universities: Manager's satisfaction toward financial strategies - It is an approach by measuring manager's satisfaction toward current financial strategies. The purpose of this indicator is to see whether a university has proven strategies that could effectively lead managerial behaviors to meet current and future challenges. Manager's opinions can serve as valid measures in the measurement of effectiveness of financial strategies. The indicator can be measured by manager's evaluations on the current financial strategies. The evaluations may include manager's critical reflections of financial strategies and thereby it may leads to a chance of revising current financial strategies. However, because of manager's subjective judgments, the measurement may encounter reliability issues. The measurement should be of cautiousness (De Boer, 2007). 
Annual amount of investment in infrastructures - The indicator measures the total expenditures on infrastructures in universities. The infrastructures provide the basic needs for universities to achieve long term development. It will also affect the long term financial positions in the universities. In CUC report (2006), a similar indicator is total cost of remedial investment on estates and infrastructure.

\section{Human Resources (Employees)}

The relation between human resource management and organizational performance has well been examined in human resource literatures (El-Hefnawy, 2014, Jeong, 2014). However, the systematic performance measurement on human resource might be very rare at this moment. Marz et al. (2012) defined strategic human resource to organizational performance as planned human resource deployment and activities that enable organizations to achieve goals. As universities do not have clear goals, it is difficult to measure the extent to which the goals are achieved by means of human resource management. Performance measurement on human resource might be more appropriate to measuring human capital and effectiveness of policies and practices in universities. They are two important criteria in evaluation of human resource performance:

\section{Human Capital}

The importance of human capital to universities builds on whether the universities can provide with qualitative and competitive academic personnel to meet the needs of academic activities. Human capital can be seen as the stocks of skills and knowledge that are capable of producing value. These skills and knowledge are embodied in people.

Percentage of Success in recruitment - Recruitment is important for universities to store and maintain a certain level human capital for university services. It caters for the needs of universities to fulfill its available job positions. Recruitments can be divided into full-time and part-time recruitments. Fulltime recruitments to the universities mean more than souring for candidates to do the jobs. It means a strong fit between job positions with required knowledge, skills and experience. Thus, the indicator might be more appropriate and valid here for the universities to measure the performance in human capital. The indicator measures the successful rate in the total fulltime recruitments. The results from the indicator may fluctuate because of the number of available job positions. Thus, the reliability of the measurement in recruitment ought not to be overestimated. It provides university managers with a signal of whether more resources are needed in this area to increase the success rate (Mathew, 2011)

Staff skills and staff diversity - Staff skills are broad and can be measured by variety of skills related to staff capabilities. The indicator is also used in CUC report (2006). One of methods in the measurement is by staff's language skills. As universities with large number of international students on campus, communication in English is becoming important to university staff in services. For example, percentage of staff who can speak English with min. 5.5 in IELTS (an English proficiency test) might be a valid and reliable measure in this respect but it might not be very practical in application. It needs all staff to take part in the English test, which might be very 
costly. Staff diversity is also an important indicator in staff composition in universities. It can be measured by counting the number of $\mathrm{PhD}$ students, professors and assistant professors, the number of academic staff, supportive staff, lecturers and ratio of academic staff to non-academic staff etc. As knowledge and skills are embodied in people, the indicator also provides university managers with a clear image of academic capabilities in terms of human capital stored in university staff. The measurement is a quick snapshot of how diverse of university staff could be. The indicator of staff skills and staff diversity is a helpful measurement of staff composition and staff capabilities in universities but it may also encounter difficulties in how actual these skills can be measured objectively.

Employee's age distribution - Employee's age distribution measures the average age among different groups of academic and non-academic employees. On one hand, the increasing average age of employees may decrease in university capabilities and outputs. On the other hand, it also signals the increasing experiences among university employees. The validity of this indicator in human capital may not be overestimated. It is unclear what level of average age is ideal to employees with optimal level of experiences and outputs. The employee's age distribution can be measured by percentages of employees in different age spans in the division of gender, e.g. \% of male employee in age $30-40$ and \% of employee over age 50 or 60 . It provides university managers with an image of growth patterns in age distribution among university employees. The measurement is a valid and reliable presentation of university employee's age distribution. Once the managers think the average age of employees is becoming old and is at the cost of university outputs, recruitments for new employees may get important in their agendas (Neely, 2007).

\section{HR Policies and Practices}

The effectiveness of human resource policies and practices may be measured by how these policies and practices have helped in increasing employee's job performance in addition to human capital. The importance of job performance related to organizational performance in service industry is widely documented in human resource literatures. Parmenter (2007) attributed this important connection to the uniqueness of service industry that features a flimsy and permeable boundary between organizations and their customers. Wang (2010) argued that customers often depend on the behaviors of service employees in judging the quality of service. Hence service employee's level of customer orientation becomes a key driver for customer satisfaction. Service employee's level of customer orientation can also be regarded as a leverage of service organization's economic success (Wang, 2010). Therefore, the effectiveness of human resource policies and practices play a critical role in universities. The level of individual job performance might decide what amounts of value can be created in organizational service.

Universities have both academic employees and non-academic employees. A common problem is that people's job performance cannot be directly measured. For example, how can you measure an academic employee who is sitting 10 hours a day in his office as good or bad performance? University managers can not directly measure the performance of the employee unless his paper is published by a well-known journal at some day. There is a long lagging time between inputs of 
time and efforts into making the paper and the outcome of the paper. People are not machines which their job performance can be directly seen.

Zuashkiani et.al. (2011) defined a more complicated definition of job performance as individual behavior variables that compose knowledge, skills, abilities and motivations toward organizational goals. The definition highlights the importance of employee abilities, skills, knowledge and motivations in job performance toward organizational goals. While in Kelley's model, the ability is a bigger word that contains knowledge, skills and nature-born abilities. The development of performance indicators will focus on these aspects that potentially affect employee's ability and motivation in human resource management.

Expenditures on training and development - Ability can be generally defined as someone's capability of doing something, which is similar to the concept of human capital discussed above. One important indicator related to ability is employ's training and development. It can be measured by annual expenditures on employee's training and career development in universities. The indicator is also used in CUC report (2006). The expenditures on job training, career development and opportunities can have a directly impact on employee's job performance. Abu Bakar (2015) argue that the relationship between training and labor productivity exists not only at individual level but also at organizational level. However, the effect of training and development to employee's job performance should not be overestimated. It is only one of the factors that may effect on employee's job performance. Besides, it may take overtime before any significant job performance might be seen from employees as a result of training and development programs.

Employee motivation- Motivation is another factor that may has a great influence on employee's job performance. Bird (2005) identified several kinds of motivations associated with employee's job performance in government agencies, including structure of task/work, task motivation, public service motivation and individual motivation. The motivations can be grouped into intrinsic and extrinsic motivations. Motivation factors vary, which may include all sorts of briefs, values, needs and wants. Without motivation, employee's job performance might be comprised and may not last longer, no matter how hard employees are forced to work and how talent, experienced and skillful the employees are.

Employee's extrinsic motivation can be measured by their level of satisfaction toward university human resource policies and practices. The use of survey is a qualitative method for detecting employee's satisfaction toward the policies and practices such as welfare, promotion and pension etc. The policies and practices may construct the main source of extrinsic motivation factors. The use of survey by employee evaluations is a useful mechanism to know what employee's general opinions in these aspects. For university management, the data from the indicator may only be referential because of subjective judgments by employees. Besides, employee's motivation may also be measured by employee's turnover and sick leave. Employees with less motivation may negatively quit the job or be sick leave. Their behaviors will result in a higher turnover and sick leave rate. The employee's turnover and sick leave provides a helpful mean for university managers to measure employee's motivation by their associated behaviors. However, it might be not very reliable. Even if employees with low motivation, they may still go 
to work on time by the enforcement of rigid labor contracts. The measurement also needs considerable efforts in collecting data every day and thus it may cause extra workloads for employees (Mathew, 2011).

\section{Categorization of Kpis Related to Universities Performance Evaluation}

In order to configuration of sub-variables related to KPIs that used for evaluation of university performance, models introduced by Adriana et al., Broadbent, CUC Report on the Monitoring of Institutional Performance and the use of KPI's, Kim et al., Chen et al., Lee , Hou were evaluated and Important variables were extracted from each study. Then, similar to previous section, duplicate variables removed and Variables that had a lot of overlap conceptually, merged. In each of these studies, university performance indicators are provided and they were classified. So that they can be expressed in five main categories. In other hand, the Ministry of Science and Technology in Iran have the instructions to performance assessment of major universities, that it has same category to do assessment. The result of this work is to achieve the variables that are summarized in the table 1.

Table 1. The Main Variables Extracted in the Area Kpis of University

\begin{tabular}{|c|c|c|c|c|c|c|c|c|c|}
\hline No. & Research KPI & $\begin{array}{l}\text { Kim } \\
(2014)\end{array}$ & $\begin{array}{l}\text { Lee, } \\
(2010)\end{array}$ & $\begin{array}{l}\text { Chen et al } \\
\text { (2006) }\end{array}$ & $\begin{array}{l}\text { Hou, } \\
\text { (2011) }\end{array}$ & $\begin{array}{c}\text { CUC } \\
\text { Report } \\
(2006)\end{array}$ & $\begin{array}{l}\text { Broadbent } \\
\text { (2007) }\end{array}$ & $\begin{array}{l}\text { Adrian } \\
\text { a et al } \\
(2008)\end{array}$ & Area \\
\hline 1 & Researcher FTE & * & & * & & $*$ & * & & \multirow{10}{*}{ 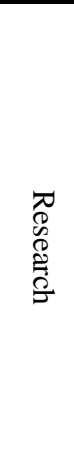 } \\
\hline 2 & Number of sponsors & * & * & * & & & & * & \\
\hline 3 & granted applications & * & & & * & & * & & \\
\hline 4 & Number of publications & * & & & * & * & * & & \\
\hline 5 & Number of doctorate conferred & * & & & & * & & & \\
\hline 6 & $\begin{array}{l}\text { Exploitation of Intellectual } \\
\text { Property (IP) }\end{array}$ & * & * & & & * & & & \\
\hline 7 & $\begin{array}{l}\text { Number of successful } \\
\text { entrepreneurs }\end{array}$ & * & * & & & & & & \\
\hline 8 & Citations & * & & $*$ & & * & * & & \\
\hline 9 & Memberships & * & * & * & & * & & & \\
\hline 10 & Awards & * & & * & & & & * & \\
\hline 11 & Research ranking & * & & & & * & & & \multirow{6}{*}{ 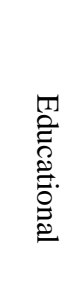 } \\
\hline 12 & $\begin{array}{l}\text { Intake of graduates and } \\
\text { undergraduates }\end{array}$ & & * & & * & * & * & & \\
\hline 13 & $\begin{array}{l}\text { Number of BA/MA degree } \\
\text { programs }\end{array}$ & & * & & * & * & * & & \\
\hline 14 & Staff FTE & & & * & & & & & \\
\hline 15 & Student/ academic staff ratio & & & * & & * & & & \\
\hline 16 & Graduation & & & & * & * & * & & \\
\hline 17 & Student satisfaction & & & * & & & * & $*$ & \multirow{7}{*}{$\begin{array}{l}0 \\
0 \\
0 \\
0 \\
心 \\
心\end{array}$} \\
\hline 18 & Study efficiency & & & & & * & * & & \\
\hline 19 & Retention rate & & & * & & * & & * & \\
\hline 20 & Drop-out rate & & * & * & & & & * & \\
\hline 21 & Average contact hours & & & * & & & & * & \\
\hline 22 & Graduation satisfaction & & & & $*$ & & * & & \\
\hline 23 & Employment & & & * & $*$ & & & * & \\
\hline 24 & Research income & * & * & & & * & & & \multirow{3}{*}{ — } \\
\hline 25 & Research indirect cost recovery & * & * & & & * & * & & \\
\hline 26 & $\begin{array}{l}\text { Share in funding (3rd party or } \\
\text { governmental) }\end{array}$ & * & * & & & * & & & \\
\hline
\end{tabular}




\begin{tabular}{|c|c|c|c|c|c|c|c|}
\hline 27 & Tuition fees and other services & & * & * & * & * & \\
\hline 28 & Short/long-term financial position & & & & & * & \\
\hline 29 & Operating cost recovery & & * & & * & & * \\
\hline 30 & Surplus/deficit as \% of income & & & & * & * & \\
\hline 31 & Current ratio & & & & & * & \\
\hline 32 & Debit ratio & & * & & & & * \\
\hline 33 & $\begin{array}{l}\text { Manager’s satisfaction toward } \\
\text { financial strategies }\end{array}$ & & & & & * & \\
\hline 34 & $\begin{array}{l}\text { Annual amount of investment in } \\
\text { infrastructures }\end{array}$ & * & & & * & * & \\
\hline 35 & $\begin{array}{l}\text { Expenditures on training and } \\
\text { development }\end{array}$ & & & & * & * & \\
\hline 36 & $\%$ of success in recruitment & * & & & & * & \\
\hline 37 & Staff skills and staff diversity & & & & * & & 黾首 \\
\hline 38 & Employee’s age distribution & & & & * & & $\overrightarrow{\tilde{E}} \vec{g}$ \\
\hline 39 & Employee motivation & & & & * & & \\
\hline
\end{tabular}

\section{Conclusion}

Much research has been done in terms of assessing the performance of educational institutions. Considering that education in universities and research done on a massive scale, the need to evaluate the university performance is not less than educational institutions. In this paper, using indicators that have been proposed by various researchers, a model for evaluating the performance of university was presented. In brief, this model is shown in following figure:

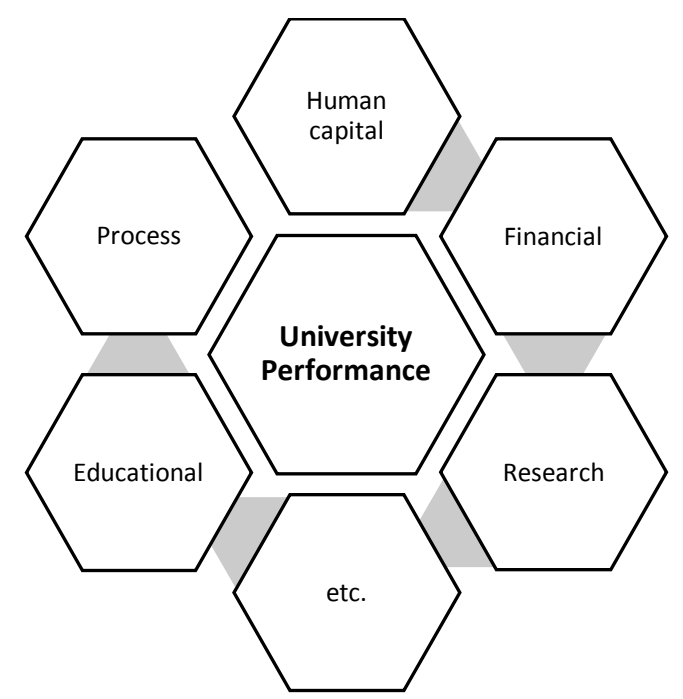

Figure 1. The university performance evaluation model

The valorization is an increasingly important dimension to the performance in the university. The development of the dimensions in the framework may not be the ultimate solution to capture all performance areas but it hopes to find key and common grounds that may be interested by managers in most universities. The two main dimensions can be further divided into four subdimensions. They are research, education, finance and human resources, which the research and educational performance is the core and the financial and human resource performance is the enablers. Research and educational activities are most common activities in wide categories of 
universities. Financial and human resources are very important to university management. The development of sub-dimensions may not be for capturing all the performance areas but it hopes to find key and common grounds in most universities.

It is recommended for future research that for each of the index, respective weight calculated using quantitative methods. Example of this work by Hou (2011) was conducted using AHP method.

\section{References}

Adriana T. Reka T, V., Vasile C., Alexandra M. (2008). Implementing the balanced scorecard in public institutions for higher education in Romania: an innovative project, European Journal of Management.

Bakar, N. R. A., Mustapha, M., Kasim, M. D. N. A. A., \& Amiruddin, R. (2015). The use of Key Performance Indicator in Malaysian Government-Linked Company.

Barnabè, F., \& Riccaboni, A. (2007). Which role for performance measurement systems in higher education? Focus on quality assurance in Italy. Studies in Educational Evaluation, 33(3-4), 302-319.

Bird, S. M., David, C., Farewell, V. T., Harvey, G., Tim, H., \& Peter, C. (2005). Performance indicators: good, bad, and ugly. Journal of the Royal Statistical Society: Series A (Statistics in Society), 168(1), 1-27.

Broadbent, J., \& Laughlin, R. (2007). Performance Management Systems in and of Higher Education Institutions in England: professionalism, managerialism and management. Roehampton University Research Papers, Roehampton University, Roehampton.

Chen, S. H., Yang, C. C., \& Shiau, J. Y. (2006). The application of balanced scorecard in the performance evaluation of higher education. The TQM magazine, 18(2), 190-205.

De Boer, H. F., Enders, J., \& Leisyte, L. (2007). Public sector reform in Dutch higher education: The organizational transformation of the university. Public Administration, 85(1), 27-46.

El-Hefnawy, M. R. M., El-Bastawissy, A. H., \& Kadry, M. A. (2014). Towards a Composite index for measuring the higher education institutions in Egypt. In Science and Information Conference (SAI), (pp. 31-41). IEEE.

Jeong, M. E., \& Yu, S. J. (2014). A Study on BSC development and Strategy execution plan for Private education service field. Journal of the Korean Society for Quality Management, 42(3), 425-444.

Kim, keung-hee, (2014). "Development of BSC performance evaluation model for University lifelong education center.” PhD diss., Dong-Eui University.

Lee, joo-seong. (2010). "A Case Study on the Introduction of BSC System in the University.” Korea national university of Transportation, Theses Collection.

Marz, L. (2012). Key performance indicators for the evaluation of balanced lines. In Simulation Conference (WSC), Proceedings of the 2012, Winter (pp. 1-10). IEEE.

Mathew, J., Lee, J., Ni, J., and Sarangapani, J. (2011). Engineering Asset Management, pages 15.

Neely, A. (Ed.). (2007). Business performance measurement: Unifying theory and integrating practice. Cambridge University Press.

Parmenter, D. (2007). Key performance indicators: developing, implementing, and using winning KPIs. John Wiley \& Sons.

Wang, X. (2010). Performance measurement in universities: Managerial Perspective (Master's thesis, University of Twente).

Xiaomei, H. (2011). Research on the performance evaluation of University Library in Tianjin. Energy Procedia, 5, 1148-1152.

Zuashkiani, A., Rahmandad, H., \& Jardine, A. K. (2011). Mapping the dynamics of overall equipment effectiveness to enhance asset management practices. Journal of Quality in Maintenance Engineering, 17(1), 74-92. 